\title{
Ice cover decay and heat balance in Lake Kilpisjärvi in Arctic tundra
}

\author{
Matti LEPPÄRANTA, ${ }^{1,2 *}$ Elisa LINDGREN, ${ }^{1}$ Lijuan WEN, ${ }^{2}$ Georgiy KIRILLIN ${ }^{3}$ \\ ${ }^{1}$ Institute of Atmospheric and Earth Sciences, University of Helsinki, Finland; ${ }^{2}$ Key Laboratory of Land Surface Process and Climate \\ Change in Cold and Arid Region, Northwest Institute of Eco-Environment and Resources, Chinese Academy of Sciences, Lanzhou, \\ China; ${ }^{3}$ Department of Ecohydrology, Leibniz-Institute of Freshwater Ecology and Inland Fisheries, Berlin, Germany
}

\begin{abstract}
To gain more understanding of lake ice melting process, field research was carried out in an arctic tundra lake, Kilpisjärvi (surface area $37.1 \mathrm{~km} 2$, maximum depth $57 \mathrm{~m}$ ) in the melting periods of 2013 and 2014 . The heat budget of the ice cover was dominated by the radiation balance; turbulent heat fluxes were large in 2013 due to warm air advection but small in 2014. Transmittance of solar radiation through ice was 0.25 in 2013 and 0.10 in 2014, snow-ice was absent in 2013 but in 2014 accounted for $50 \%$ of the ice cover. The melting rate was $4.4 \mathrm{~cm} \mathrm{~d}^{-1}$ in 2013, $1.9 \mathrm{~cm} \mathrm{~d}^{-1}$ in 2014. The portions of surface, bottom and internal melting were, respectively, $2.9,1.0$ and $0.5 \mathrm{~cm} \mathrm{~d}^{-1}$ in 2013 and $0.8,1.0$ and $0.1 \mathrm{~cm} \mathrm{~d}^{-1}$ in 2014 . Internal melting was realized in increase of ice porosity. In 2013 a rapid ice breakage event completed the ice breakup in short time when ice porosity had reached $40-50 \%$. A lake ice melting model should include the thickness and porosity of ice, with porosity connected to an ice strength criterion.
\end{abstract}

\section{INTRODUCTION}

Seasonal formation of ice cover is an essential feature of natural waters of the boreal and polar climatic zones. Seasonal ice regime (ice phenology) of numerous lakes in the northern polar region determines the climatic balance of precipitation and evaporation, as well as the ecosystem state and the water quality of the lakes themselves. Still, the energetics of seasonal ice cover formation on polar lakes remains poorly investigated to date. A steady trend to the shortening of the ice season during the last 100-150 years has been reported in several recent studies (Magnuson et al., 2000; Benson et al., 2012; Bernhardt et al., 2012; Yao et al., 2016; Karetnikov et al., 2017), attributed to global climate warming. Estimation of the consequences of these phenological changes requires a quantification of the physical mechanisms that control the formation and melting of ice.

Along with the ice climatology, motivation to examine

Corresponding author: matti.lepparanta@helsinki.fi

Key words: Lake ice; melting; solar radiation; heat budget; light transfer.

Edited by: Franco Tassi, University of Florence, Italy

Received: 6 December 2018.

Accepted: 4 February 2019.

This work is licensed under a Creative Commons Attribution NonCommercial 4.0 License (CC BY-NC 4.0).

${ }^{\circ}$ Copyright: the Author(s), 2019

Licensee PAGEPress, Italy

J. Limnol., 2019; 78(2): 163-175

DOI: 10.4081/jlimnol.2019.1879 ice-covered lakes has been their ecology and fishery (Salonen et al., 2009; Kirillin et al., 2012), practical issues such as ice bearing capacity and loads (Ashton, 1985; Masterson, 2009), and weather conditions (Yang et al., 2013). Recently, Arctic lake systems have turned to a subject of intense research related to the global carbon budget and associated climate warming (Zimov et al., 2006; Walter et al., 2007). The lake and pond systems of the arctic tundra are mediators of the terrestrialatmospheric exchange of methane and carbon dioxide in arctic regions - the largest potential carbon source due to thawing permafrost (Travnik, 2014). The effects of freezing of water bodies throughout from surface to bottom, under-ice heat transport, and ice melting on the production and release of greenhouse gases are undoubted but largely unknown. Also, heat exchange between the water body and the underlying sediments is of crucial importance for the production of these gases. Similar to the Arctic, the high-altitude regions possess a tundra-like climate with developed lake systems as inherent features of it. In particular, the Tibetan Plateau is covered by thousands of lakes, more than 1200 of them having an area $>1 \mathrm{~km} 2$ (Ma et al., 2011), and undergoes warming trends comparable to those in Arctic (Guo and Wang, 2012; Duan and Xiao, 2015). The major difference in the response of ice regime to the climate change of arctic and low-latitude alpine lake systems is determined by the solar radiation climate (Wen et al., 2016). In that sense, a quantification of the solar radiation input to the seasonal ice melt relative to the boundary fluxes at the ice surface and bottom provides an important insight into the lake response to warming on regional to global scales.

In winter, snow and ice cover effectively insulate the liquid water body of a lake from atmospheric heat and momentum fluxes and deposition, as well as to a large degree from solar radiation. When the melting phase begins 
and snow cover disintegrates, a large fraction of sunlight penetrates the ice. Water warms up, resulting in convective mixing (Bengtsson et al., 1996; Malm et al., 1998; Mironov et al., 2002), and initiating primary production (Kelley, 1997; Salonen et al., 2009). Part of the solar heat is returned from water to the ice bottom (Jakkila et al., 2009; Leppäranta et al., 2010). Hence, ice decay is forced primarily by solar radiation, and the optical properties of ice are highly important for it. However, empirical methods to predict ice decay are usually based on the positivedegree-days of air temperature, whose connection to solar radiation is indirect.

We examine here the ice mass and heat balance together with the connection between ice structure and transfer of solar radiation in the melting phase in Lake Kilpisjärvi in the arctic tundra of Finland. This lake is frozen for 7-8 months annually, and the annual maximum thickness of ice is close to one meter. The fieldwork was performed in two subsequent years 2013 and 2014, at the same late stage of the seasonal ice cover development in May, but at strongly different synoptic conditions: "extremely warm" (2013) and "typical" (2014). By this, we were able to analyze in detail the heat and mass budget of lake ice cover at different relationships between the radiation and surface fluxes, as well as at different rates of ice heating. In the following, we concentrate on the ice cover, while the lake water dynamics under ice have been reported elsewhere (Kirillin et al., 2015, 2018). Melting lasted about one month. The solar radiation provided the main forcing but warm air advection occasionally brought large amount of sensible heat. Ice melted mostly at the upper surface and in the interior. The net surface heat flux was compared with the melting rates of ice and snow that provided a reference to validate the estimated total heating.

\section{METHODS}

\section{Research site}

Lake Kilpisjärvi is an arctic tundra lake located in the Scandinavian Mountain Chain in northwest Finland at $69^{\circ}$ $03^{\prime} \mathrm{N}$ and $20^{\circ} 50^{\prime} \mathrm{E}$. The distance to the North Atlantic Ocean is about $60 \mathrm{~km}$. The lake is surrounded by fells rising up to $550 \mathrm{~m}$ above the lake surface level, which itself is at an altitude of $473 \mathrm{~m}$ above sea level. Lake Kilpisjärvi has a total area of $37 \mathrm{~km} 2$ with eight small islands, the average depth is $19.5 \mathrm{~m}$ and the maximum depth is $57 \mathrm{~m}$. The run-off to the lake originates from small mountain brooks of the catchment area. The outflow goes along a river to the Gulf of Bothnia, Baltic Sea. Lake Kilpisjärvi is an ultra-oligotrophic clear-water lake. There are no industrial or agricultural activities in the drainage basin, apart from reindeer herding. The Kilpisjärvi village at the lake has less than 100 inhabitants but about 40,000 tourists visit the region annually.

In the northern bay on the east side of Lake Kilpisjärvi there is a routine ice and snow monitoring station of the Finnish Environment Institute (Korhonen, 2005). In the period 1952-2015 the mean freezing and breakup dates were November 9 and June 18, and the earliest and latest breakup dates were June 2 and July 1 . The length of the ice-covered period became shorter by 3.5 days per decade, mainly due to later freezing date (Lei et al., 2012). The average maximum annual ice thickness was $90 \mathrm{~cm}$ (the range was $77-114 \mathrm{~cm}$ ), reached on April 14. The mean fraction of snow-ice was $20 \%$.

Weather data are available from the Kilpisjärvi Biological Station (KBS) and Enontekiö Kilpisjärvi Kyläkeskus (EKK) of the Finnish Meteorological Institute. The annual mean air temperature is between $4^{\circ} \mathrm{C}$ and $-1{ }^{\circ} \mathrm{C}$, with monthly mean below $0^{\circ} \mathrm{C}$ from October to April. Snow thickness on ground is on average $90 \mathrm{~cm}$ in March-April. Permafrost is found only in small patches in the region (Kohout et al., 2014).

A study on the annual heat budget of Lake Kilpisjärvi was performed by Leppäranta et al. (2017) based on lake station (float) data from 2007-2009. The heat budget was dominated by the radiation balance, which was as low as $-50 \mathrm{~W} \mathrm{~m}^{-2}$ in fall and increased up to $100 \mathrm{~W} \mathrm{~m}^{-2}$ in ice melting period. Turbulent heat fluxes were significant before freeze-up in fall with absolute values up to $30 \mathrm{~W}$ $\mathrm{m}^{-2}$, but in the ice season they were small except that occasionally sensible heat flux became significant. The observed evolution of ice thickness was consistent with the surface heat flux in the ice season.

\section{Data collection}

The field campaigns were performed in May-June 2013 and 2014 at the beginning of the polar day. In both years data were collected on ice thickness and crystal structure, solar radiation transfer through the ice, as well as conductivity-temperature-depth (CTD) and photosynthetically active radiation (PAR, spectral range 400-700 nm) profiles under the ice. In addition, meteorological observations were available from KBS and EKK weather stations, including global radiation, air temperature and humidity, atmospheric pressure, and wind speed and direction. Both weather stations are located at less than $50 \mathrm{~m}$ distance from the lake shore, hence the observations represent well the conditions over the lake. These sites were located at the eastern side of the lake in the north, where two CTD-sections were taken and automatic stations were established (Fig. 1).

The radiative transfer through the ice cover was recorded by installing small scalar PAR sensors (MDS-L, Alec Electronics Co. Ltd., Kobe, Japan) above, in and under the ice (Leppäranta et al., 2010). The sensors were 
attached to a pole that was lowered to water or supported to stand on the ice. The distance between the under-ice sensor and the ice bottom was in the beginning of the measurements $10 \mathrm{~cm}$ (2013) or $30 \mathrm{~cm}$ (2014). In 2014, one sensor was fastened to an ice block to measure the light level in the ice interior. A block of ice was first cut out and a small hole was drilled to the ice bottom to preserve the ice on top of the sensor in natural condition. The sensor was lowered to the hole and fastened with slush filling, and finally the block was put back to the hole. The measurement interval was $10 \mathrm{~min}$, and the data collection periods were 26-31 May in 2013 and 21-27 May in 2014. The accuracy of the PAR sensors is $\pm 2 \mathrm{~W}$ $\mathrm{m}^{-2}$ in air and $\pm 3 \mathrm{~W} \mathrm{~m}^{-2}$ in water or ice. In addition, irradiance profiles in the water column were measured in 2013 with a spherical PAR-sensor (LI-193SA, LI-COR Biosciences, Lincoln, NE, USA) attached to a CTD-90M profiler (Sea and Sun Technology, Trappenkamp, Germany).

\section{Data processing}

The PAR sensors record the downwelling scalar quantum irradiance, $q_{\text {PAR }}$ (unit $\mu \mathrm{mol} \mathrm{m}^{-2} \mathrm{~s}^{-1}$ ). Transformation to power unit $\left(\mathrm{W} \mathrm{m}^{-2}\right)$ is given for white light by $\frac{q_{P A R}}{E_{P A R}}=4.60 \mu \mathrm{mol} \mathrm{s}{ }^{-1} \mathrm{~W}^{-1}$, where $E_{P A R}$ is the scalar irradiance power. In water and ice, the transformation coefficient depends on the colour and turbidity of the water. In Finnish and Estonian lakes, the transformation coefficient has been found to vary between 4.8 and 5.5 $\mu \mathrm{mol} \mathrm{s}{ }^{-1} \mathrm{~W}^{-1}$, the large values belonging to more turbid waters (Reinart et al., 1998). For the clear-water Lake Kilpisjärvi, the coefficient was chosen as $4.8 \mu \mathrm{mol} \mathrm{s}^{-1} \mathrm{~W}^{-1}$ since in clear-water lakes the ice cover does not much

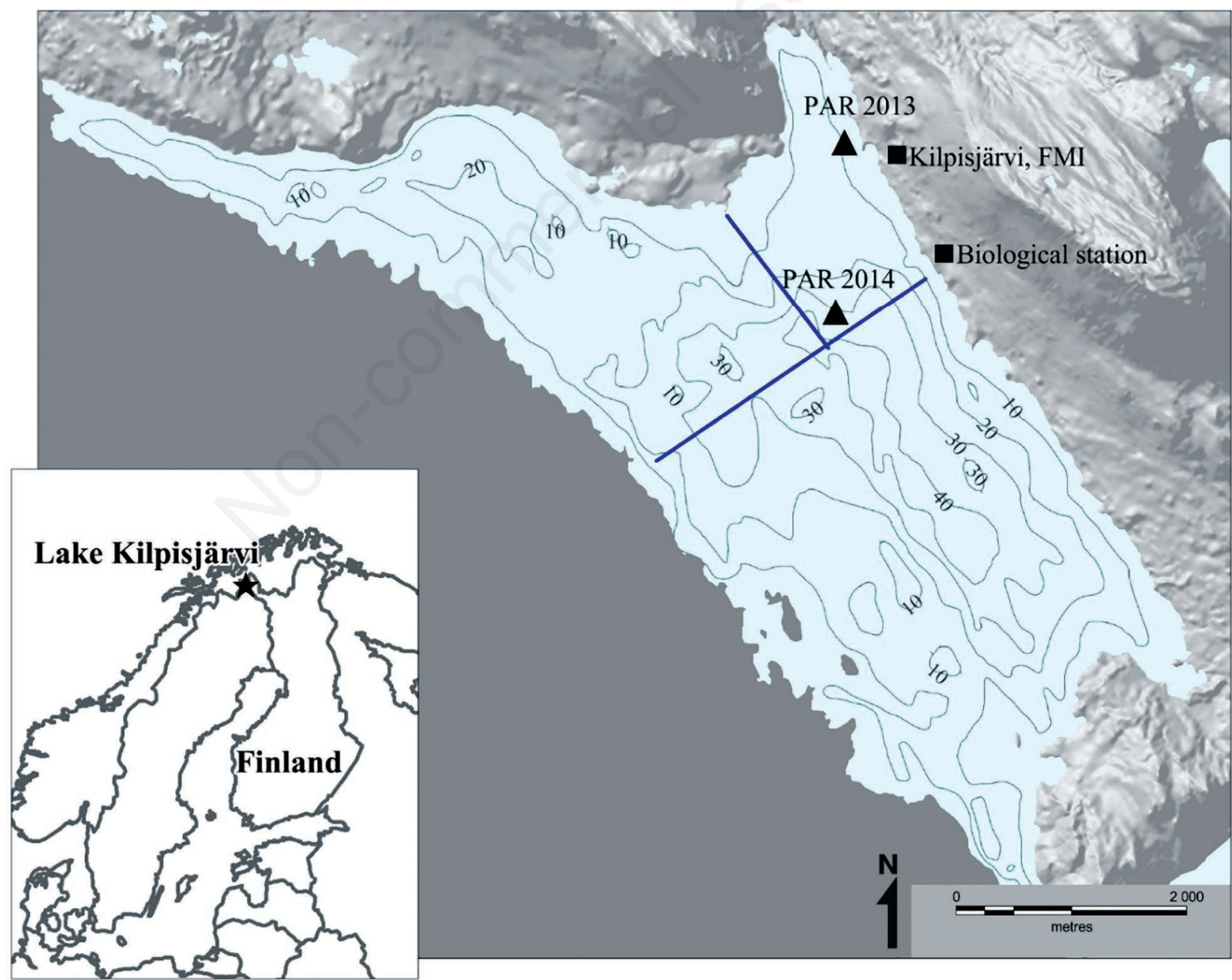

Fig. 1. Location of Lake Kilpisjärvi and the study area. The PAR stations and weather station are marked, and the dark blue lines represent the CTD-sections. 
modify the light spectrum (Lei et al., 2011). The scalar PAR values are transformed to planar assuming diffuse radiation.

Assuming that the attenuation law is similar to the Beer-Lambert absorption law, we get the expression for the irradiance as a function of depth as (Arst et al., 2006):

$q_{P A R}(z)=(1-\alpha) q_{P A R}\left(0^{-}\right) \exp \left(-\int_{0}^{z} \kappa d z^{\prime}\right)$

where $z$ is depth, $z=0^{-}$refers to the level just above the surface, $\alpha$ is albedo, and $\kappa$ is the attenuation coefficient. This gives the total light absorption in the ice cover of thickness $h$, and in the water beneath, respectively, as:

$$
\begin{aligned}
& q_{P A R, i}=q_{P A R}(0)-q_{P A R}(h) \\
& q_{P A R, w}=q_{P A R}(h)
\end{aligned}
$$

The ratio $\frac{q^{P A R, w}}{q^{P A R\left(0^{-}\right)}}$is, by definition, the light transmittance of ice.

The ice volume $V$ per unit area can be expressed by the ice thickness $h$ and porosity $v$ as $V=(1-v) h$. It is assumed that in the melting phase the ice is isothermal with the temperature at the melting point. The mass balance is then given by (Leppäranta, 2015):

$\rho L(1-v) \frac{d h}{d t}=-\left(Q_{0}+Q_{w}\right)$

$\left.\rho L h \frac{d v}{d t}=Q_{A}=(1-\alpha)\left(1-e^{-\kappa h}\right)\right) \gamma Q_{s}$

where $\rho$ is ice density, $L$ is latent heat of freezing, $Q_{0}$ is surface heat balance, $Q_{W}$ is heat flux from water, $Q_{A}$ is absorption of solar radiation in ice, $\gamma$ is the fraction of solar radiation penetrating the surface, and $Q_{S}$ is incoming solar radiation. The absorption $Q_{A}$ represents the optical band and can be called 'sunlight'. Ice thickness is easy to measure but the porosity is less so. However, with good solar radiation data the porosity evaluation can be indirectly estimated. At $v=v^{*} \sim \frac{1}{2}$, ice breaks due to its own weight and the remains melt then fast.

For non-transparent ice $(\kappa \rightarrow \infty)$, sunlight remains at the surface, and for fully transparent ice $\left(\kappa \ll h^{-1}\right)$ sunlight goes to the water to force convective heating with a fraction of heat returning up to the ice bottom. Ice melts but by much smaller rate than in the case of nontransparent ice. When $\kappa \approx 3 h^{-1}$, the net sunlight is absorbed by the ice. At $v \sim \frac{1}{2}$ the ice breaks and then disappears rapidly. Melting is thus twice as fast as in the case of non-transparent ice. In Lake Kilpisjärvi, we have $\kappa \sim h^{-1}$, and therefore in the beginning of the melting season about half of net sunlight is absorbed in the ice and the other half in the water.

The emitted longwave radiation from the surface was obtained by assuming that the ice surface was at the melting point, which is reasonable during the melt season. The atmospheric longwave radiation was calculated by $Q_{L a}=\varepsilon_{a} \sigma T_{a}^{4}$, where $\varepsilon_{a}$ is the effective atmospheric emissivity, and $T_{a}$ is the air temperature. The emissivity was calculated as a function of cloud cover and water vapor pressure (Leppäranta and Myrberg, 2009). The turbulent fluxes were obtained with the bulk aerodynamic formulae. The heat flux from precipitation was zero in our cases (no precipitation).

In the melting season, the ice cover contains decreasing amount of latent heat $\rho L(1-v) h$, while the temperature stays at the melting point. This latent heat evolution is given by the fluxes at the surface, interior and bottom. The surface heat flux consists of absorption of solar radiation, longwave radiation, and turbulent fluxes:

$Q_{0}=S W R+L W R+T F$, or

$Q_{0}=(1-\alpha)(1-\gamma) Q_{s}+\varepsilon_{0}\left(Q_{L a}-\sigma T_{0}^{4}\right)+\left(Q_{c}+Q_{e}\right), \quad$ (eq. 4$)$

where $Q_{L a}$ is longwave radiation from atmosphere, $\sigma$ is Stefan-Boltzmann constant, $\varepsilon_{0}$ is emissivity of surface, $T_{0}$ is surface temperature, $Q_{c}$ is sensible heat flux, and $Q_{e}$ is latent heat flux. The heat flux into the ice interior is given by eq. (3b).

\section{RESULTS}

\section{Ice and snow cover}

The two study periods were quite different. The ice season of 2013 can be characterized as "extreme": after colder than average winter, an extraordinarily warm and cloudless weather developed in the end of May and early June, when daytime maximum air temperature reached $25^{\circ} \mathrm{C}$. The ice melting rate was as high as $4.6 \mathrm{~cm}$ per day, the ice breakup took place on 3 June, which was the second earliest date since the start of ice observations in 1953. The prevailing weather during the field campaign in May 2014 was in turn normal, close to the climatic mean: the daytime maximum temperature stayed mostly around $5^{\circ} \mathrm{C}$, and at night the temperature dropped to close to $0^{\circ} \mathrm{C}$, the coldest recorded value was $-3.1{ }^{\circ} \mathrm{C}$. Ice breakup took place on June 19, which is at the long-term average (Fig. 2b, Tab. 1). The histogram of the breakup dates (Fig. 2b) is negatively skewed so that the probability of breakup date before midJune is only $22 \%$. Fig. 2a shows the melting rates in the study years compared with the average. This reflects the importance of solar radiation with increasing melt rates, and qualifies the melting season of 2013 as an extreme one.

Ice and snow thickness records by the Finnish Environment Institute show that both winters were cold: the maximum annual ice thickness was more than the 
long-term average (Tab. 1). In 2013 there was $20 \%$ of snow-ice (normal) but in 2014 the fraction was more than $50 \%$. The ice broke up very early in 2013 but at normal time in the following year. Overall, during the melting phase the ice cover was patchy; in areas where the ice was dry and appeared white the bearing capacity remained high almost until the break-up day, whereas in darkcoloured and wet areas the ice was fragile (Fig. 3).

\section{Ice structure, "extreme" year}

At the beginning of May 2013, the snow cover on the lake ice was $20 \mathrm{~cm}$ thick and started to melt. At, that time, the ice thickness at the routine observation site amounted to $90 \mathrm{~cm}$. Ice started to decay in mid-May after most of the snow was gone. At the beginning of the field campaign, on 24 May, the ice thickness varied lake-wide between $37 \mathrm{~cm}$ and $60 \mathrm{~cm}$ with a thin $0-4 \mathrm{~cm}$ layer of slush partly covering the ice. Snow-ice had already melted. Internal melting at the crystal boundaries had turned the ice cover to candled structure. The ice thickness was at the ice site on 25-26 May about $50 \mathrm{~cm}$, and afterwards the ice cover was too fragile to walk on. A measure of the ice thickness evolution was obtained from the PAR-station, where between the installation and dismantling (March 26 and 31), the ice thickness of 50 $\mathrm{cm}$ decreased to $25 \mathrm{~cm}$ resulting in an extremely rapid rate, averaging to $5 \mathrm{~cm}$ per day that corresponds to the net heat gain of 100-160 $\mathrm{W} \mathrm{m}^{-2}$ depending on the porosity.

Ice cover during the measurement period in May 2013 consisted only of columnar congelation ice (Fig. 4a). The thick section photographs show tilted gas bubble strings, which are already clear in the sample picture on the left. The origin of the tilted bubble strings is not clear but they have possibly been formed due to internal deterioration by solar radiation. The thin sections are not very clear but they show large macro crystals with length $10-20 \mathrm{~cm}$ and width up to $5 \mathrm{~cm}$.

A couple of meters wide ice-free margins, known as moats, had formed along the shoreline by 24 May and became wider as the melting progressed. The ice breakup took place during the field campaign, on June 3, preceded by warm, calm days which kept the fragile ice cover unbroken. On the break-up day, the average wind speed rose to $4-5 \mathrm{~m} \mathrm{~s}^{-1}$ and even though the lake was about $90 \%$ ice-covered, the ice was gone in 10-15 hours.

\section{Ice structure, "normal" year}

In 2014, the maximum ice thickness reached $97 \mathrm{~cm}$ (Tab. 1). At the end of April, the mean snow and ice thicknesses were $20 \mathrm{~cm}$ and $90 \mathrm{~cm}$, respectively. Snow

Tab. 1. Seasonal and average ice characteristics in the study winters compared to climatology from Lei et al. (2012): freeze-up and breakup from 1952-2010, ice thickness from 1981-1990, and snow on lake ice from 1977-2010.

\begin{tabular}{lcccc} 
& 2013 & 2014 & Mean & SD \\
Maximum ice thickness (cm) & 95 & 97 & 90 & 7.5 \\
- Congelation ice & 75 & 45 & 20 & 17.3 \\
- Snow-ice & 20 & 52 & April 14 & 17.1 \\
- Day of occurrence & March 10 & April 30 & 37 & $14.9 \mathrm{~d}$ \\
\hline Maximum snow thickness (cm) & 23 & 20 & March 4 & 9.1 \\
- Day of occurrence & April 10 & April 25 & June 18 & $34.4 \mathrm{~d}$ \\
\hline Ice breakup date & June 3 & June 19 & & $8.8 \mathrm{~d}$
\end{tabular}
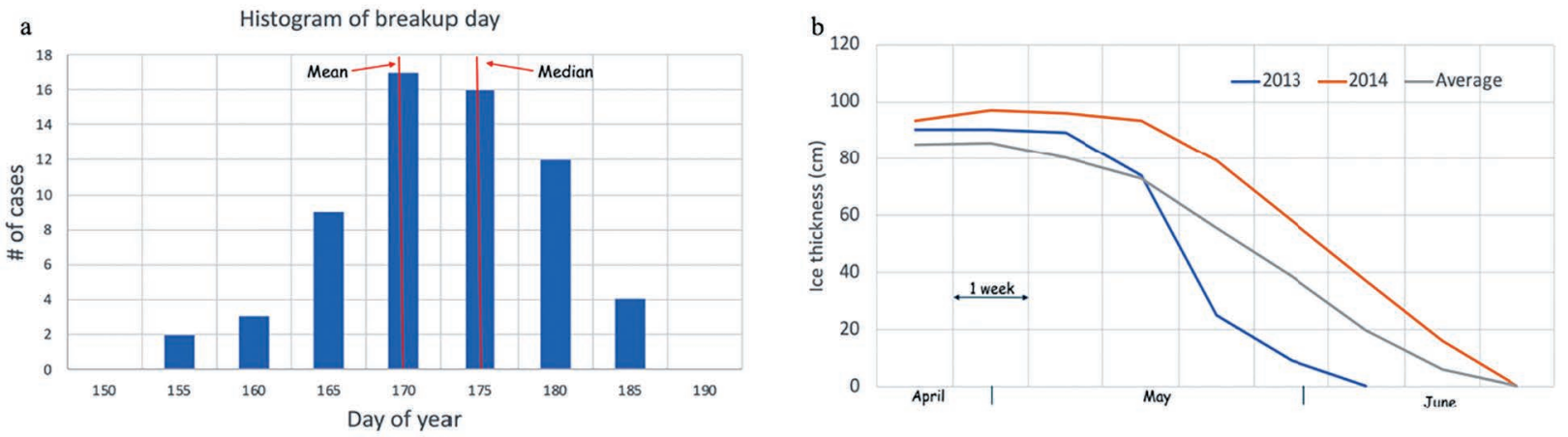

Fig. 2. a) Histogram of ice breakup dates 1953-2015. b) Melting of ice in the study years and the average over 2000-2015. 
disappeared by the beginning of the field campaign, on 20 May. Until then ice thickness stayed at around $90 \mathrm{~cm}$. with a layer of slush on top of the ice in some spots (Fig. 3). According to the ice thickness observations at the PARstation, the initial thickness of $90 \mathrm{~cm}$ decreased to $82 \mathrm{~cm}$ over the six days (May 22-28) resulting in a low melt rate of $1.3 \mathrm{~cm}$ per day. The upper half of the ice was snow-ice and captured most of the internal melting. The average slush layer thickness increased from $3 \mathrm{~cm}$ to $13 \mathrm{~cm}$ due to melting and deterioration with large spatial variability, the standard deviation was 8-9 cm. Until May 24, the water level in a drill hole was below the top of the solid ice, but on May 26 after the significant increase in the amount of slush, solid ice was on average $2.5 \mathrm{~cm}$ below the water surface.

The structure of the ice cover was more layered in 2014 compared to the simple structure in 2013 (Fig. 4b). The sample was $94 \mathrm{~cm}$ thick consisting of deteriorated top layer $(21 \mathrm{~cm})$, solid snow-ice layer $(28 \mathrm{~cm})$ and congelation ice layer $(45 \mathrm{~cm})$. In the top layer there was a $6 \mathrm{~cm}$ thick small-grained snow-ice cover and $15 \mathrm{~cm}$ thick layer of slush trapped below. In the solid snow-ice layer the crystal size was 2-10 $\mathrm{mm}$, and congelation ice layer consisted of long columnar crystals.

\section{Light transfer through ice}

We did not have measurements of albedo but that was estimated on the basis of earlier field studies (Arst et al.,
2006; Leppäranta et al., 2017). The chosen representative albedo values were 0.2 for the wet congelation ice in 2013 and 0.4 for the wet snow-ice in 2014. The choice of albedo was not arbitrary but restricted by the measured incident irradiance and irradiances in ice and below ice. Light attenuation coefficient was estimated daily from the measurements at solar noon by using the PAR irradiance above and under the ice. There was a weak diurnal cycle in the attenuation coefficient (Leppäranta et al., 2010) but estimating had large uncertainty at low sun angles. In both years the ice thickness decreased, which meant that the distance between the under-ice sensor and ice bottom increased, i.e. the under-ice irradiance data included the influence of ice and a thin $(10-35 \mathrm{~cm})$ layer of lake water.

The PAR data show the highly different conditions in 2013 and 2014 (Fig. 5). The daily maximum downwelling scalar PAR irradiance was $600-700 \mathrm{~W} \mathrm{~m}^{-2}$ every day in 2013 since the prevailing condition was clear sky, but in the following year the range was $400-800 \mathrm{~W} \mathrm{~m}^{-2}$. The net solar radiation was much higher in 2013 due to the lower albedo. The surrounding fells shade the lake, therefore night-time irradiance during the polar day, when solar altitude is low, dropped to almost zero. The congelation ice in 2013 kept quite clear with average optical thickness $\kappa^{-1} \approx 2 \mathrm{~m}$, but for the snow-ice dominated year 2014 the optical thickness was around $60 \mathrm{~cm}$. The fractionation of solar radiation passing the ice cover is shown in Tab. 2.
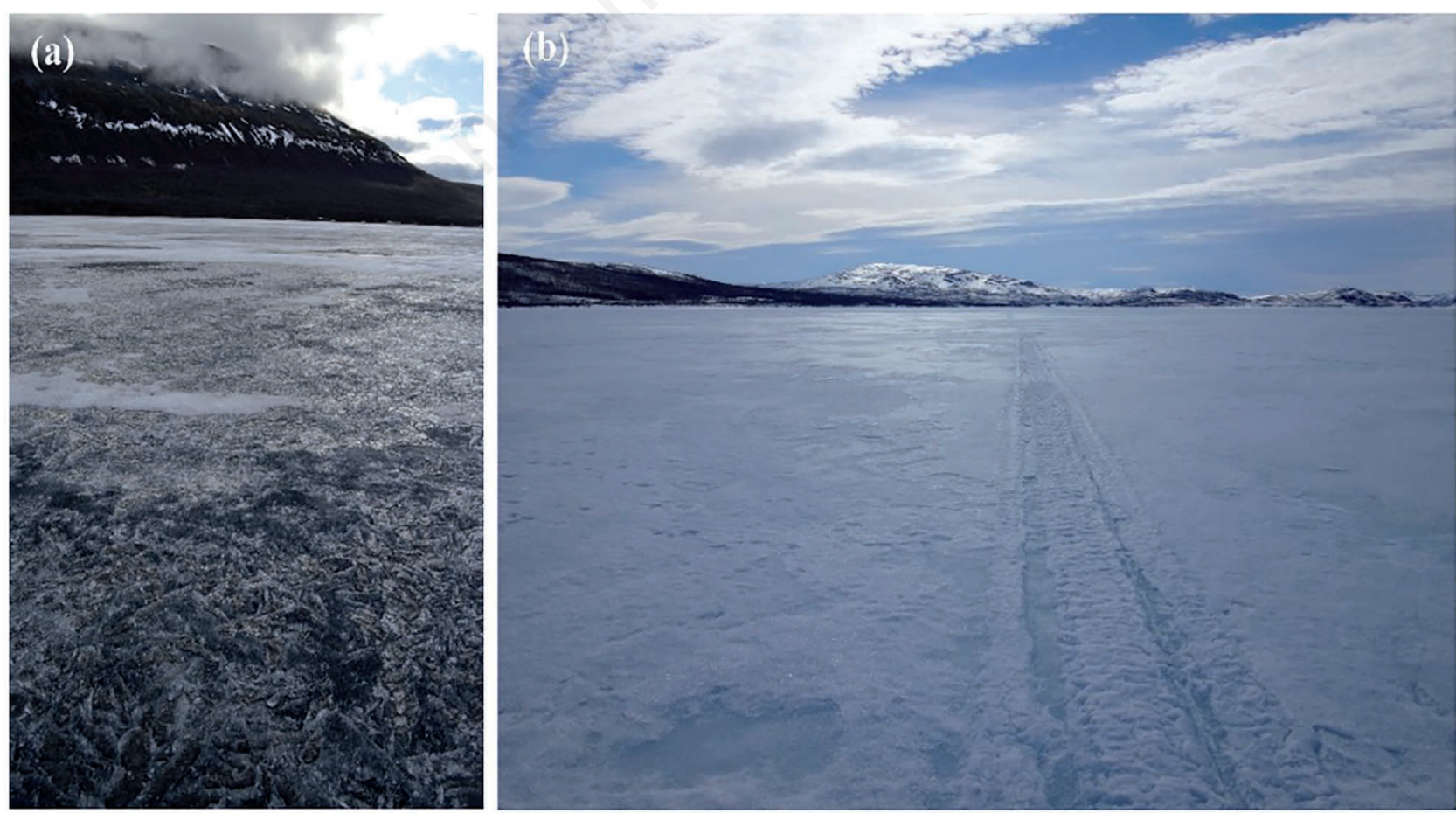

Fig. 3. Ice surface in Lake Kilpisjärvi on May 25, 2013 (a) and May 21, 2014 (b). Picture from 2014, courtesy of Kelly Graves. 
In 2013 the optical properties of the ice cover changed significantly over the six days of measurements. The attenuation coefficient decreased from $0.8 \mathrm{~m}^{-1}$ to as low as $0.2 \mathrm{~m}^{-1}$, and, consequently, the transmittance increased from 50 to $70 \%$. The strong increase in transmittance and decrease in attenuation coefficient were caused by the deterioration of the ice, which firstly decreased the ice thickness by $5 \mathrm{~cm}$ per day and secondly filled the gas pockets with melt water or lake water. The under-ice downwelling scalar irradiance had reached $300 \mathrm{~W} \mathrm{~m}^{-2}$ at noon on May 26 and further up to $500 \mathrm{~W} \mathrm{~m}^{-2}$ by May 31 .

In 2014 there were larger variations in incoming irradiance due to more cloudy conditions than in 2013. The radiation level was only $30 \mathrm{~W} \mathrm{~m}^{-2}$ beneath the ice, as is expected with the $80-90 \mathrm{~cm}$ thick ice with a dominant layer of highly scattering snow-ice. The maximum PARirradiance beneath the ice over the six days did not change and thus no similar increase in transmittance was detectable as in 2013. Similar difference was observed by
Leppäranta et al. (2010) in a lake in Russian Karelia in two years. The attenuation coefficient remained almost constant, equal to $1.7 \mathrm{~m}^{-1}$ over the five days of measurements and likewise the transmittance stayed all the time below $10 \%$. The ice conditions did not change drastically during the field campaign, except for the deterioration of the snow-ice layer, that explains the stable optical parameters of the ice.

\section{Heat budget during the melting season}

In the "extreme" melting season of 2013, the surface heat balance was governed by the incoming solar radiation (Fig. 6a). The daily net shortwave radiation (SWR) peaked to $420 \mathrm{~W} \mathrm{~m}^{-2}$ in most of the days between May 23 and June 1 due to the dominating clear sky conditions, but on June 2 and 3 the weather was cloudier, decreasing the solar heat gain (see the daily averaged values in Tab. 3). Compared to the shortwave radiation, the net longwave radiation (LWR) was smaller ranging (a)
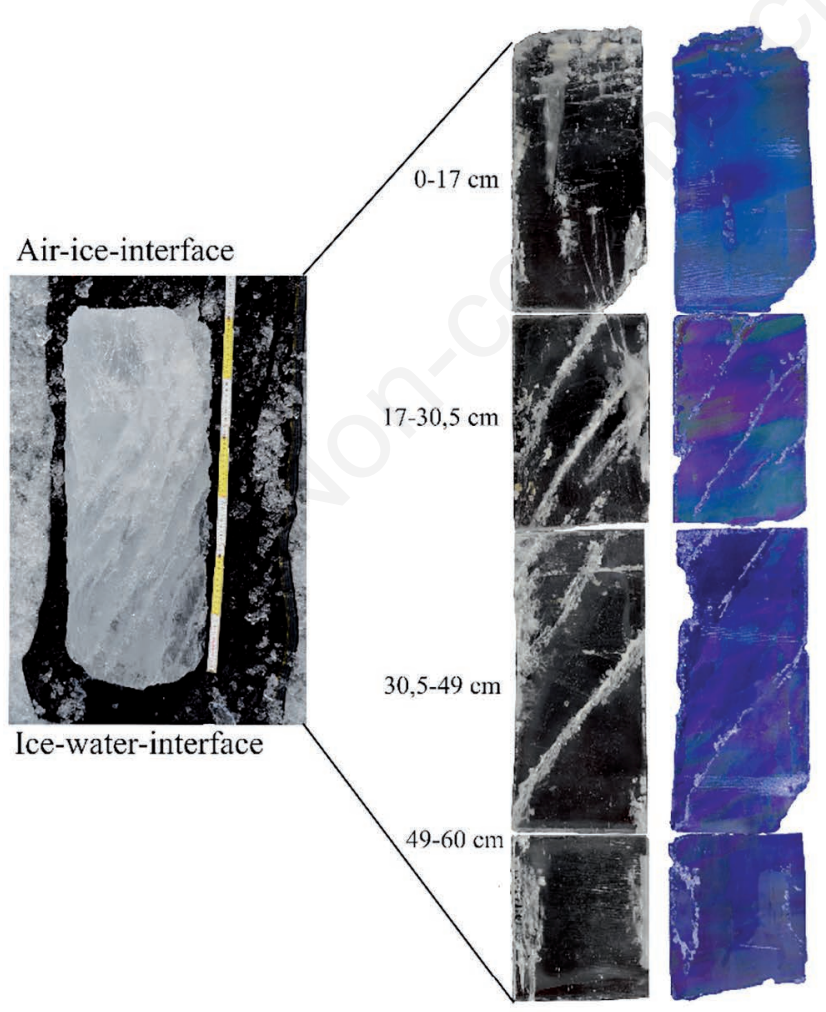

(b)

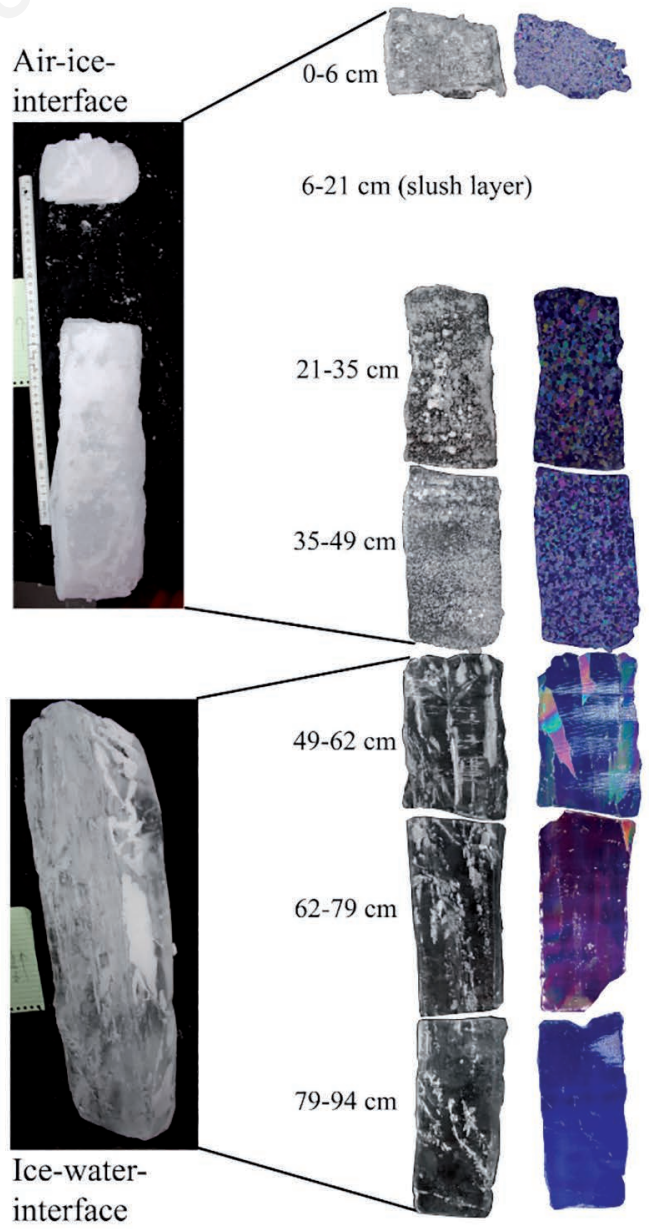

Fig. 4. Ice cores from Lake Kilpisjärvi with thick $(\approx 1 \mathrm{~cm})$ and thin sections: (a) 2013 and (b) 2014. The samples were taken in the beginning of the field periods. 
between $-55 \mathrm{~W} \mathrm{~m}^{-2}$ and $+75 \mathrm{~W} \mathrm{~m}^{-2}$. Hence, surprisingly, it was not only acting as a heat sink but instead provided large amount of heat for ice melt, with maximum daily average equal to $24 \mathrm{~W} \mathrm{~m}^{-2}$. The reason was strong downward radiation flux $Q_{L a}$ from very warm air, while the presence of ice kept the surface temperature at $0^{\circ} \mathrm{C}$ limiting the outgoing longwave radiation. The change from negative to positive net longwave radiation took place on May 27. Turbulent heat exchange between the ice and the relatively warm air was strong and had a clear diurnal cycle (Fig. 6b). Sensible heat flux stayed positive over the ten days of field campaign peaking at up to 100 $\mathrm{W} \mathrm{m}{ }^{-2}$ in daytime and decreasing to nearly zero at night. It acted only as a positive term in the surface heat budget, and the daily averages were between 18 and $45 \mathrm{~W} \mathrm{~m}^{-2}$. Latent heat flux, on the other hand, was a heat sink for the surface as a result of evaporation and sublimation, and compared to the sensible heat flux, it had lower absolute value. The minimum latent heat level was $-45 \mathrm{~W} \mathrm{~m}^{-2}$, and the range of daily means was $-10 \mathrm{~W} \mathrm{~m}^{-2}$ to $-21 \mathrm{~W} \mathrm{~m}^{-2}$ (Tab. 3). The mean Bowen ratio $Q_{c} / Q_{e}$ was -2.3 . The net effect of the turbulent fluxes on the surface heat flux was positive throughout the field campaign and averaged to $16.5 \mathrm{~W} \mathrm{~m}^{-2}, 20 \%$ of the solar radiation absorbed at the surface.

The diurnal cycle in solar radiation was strong despite the polar day, and was augmented by the shadowing from the fells surrounding the lake. The night-time income of solar radiation was very low. The net longwave radiation also dropped close to zero, and the surface radiation balance remained positive. The net surface heat flux decreased below zero in the night-time hours, otherwise the lake ice was constantly gaining a lot of heat (Fig. 6c): the daily maximum reached as high values as $450 \mathrm{~W} \mathrm{~m}^{-2}$, and on average the daily surface heat balance was between $74 \mathrm{~W} \mathrm{~m}^{-2}$ and $126 \mathrm{~W} \mathrm{~m}^{-2}$.

In the "normal" season of 2014, cloudy weather and the higher albedo of the ice cover than in 2013 were the major reasons for a relatively low level of shortwave radiation at Kilpisjärvi (Fig. 6d). The maximum amount of solar heating at the highest solar altitude was $300 \mathrm{~W} \mathrm{~m}^{-2}$, the daily average was on May 22 as low as $52 \mathrm{~W} \mathrm{~m}^{-2}$, and even the highest value reached only $85 \mathrm{~W} \mathrm{~m}^{-2}$ on May 24 (Tab.

Tab. 2. Relative distribution of solar radiation incoming into ice into outgoing radiation, absorption at the surface and interior, and transmission into water. The daily mean net irradiance was $160 \mathrm{~W} \mathrm{~m}^{-2}$ in 2013 and $118 \mathrm{~W} \mathrm{~m}^{-2}$ in 2014.

\begin{tabular}{lll} 
Component / year & 2013 & 2014 \\
Outgoing & 0.20 & 0.40 \\
\hline Surface absorption & 0.40 & 0.30 \\
\hline Interior absorption & 0.15 & 0.20 \\
\hline Transmission & 0.25 & 0.10
\end{tabular}
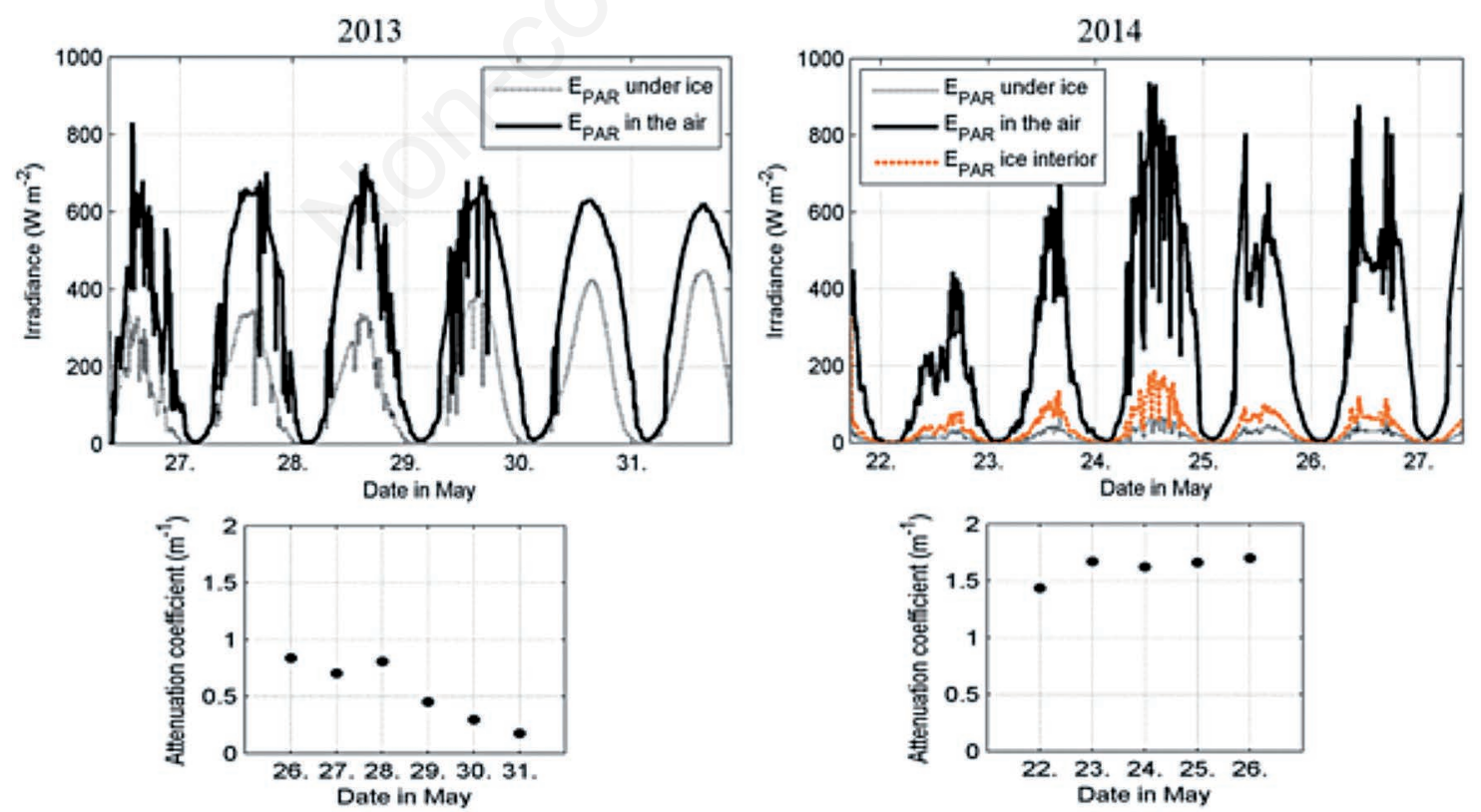

Fig. 5. Light transfer measurements through Lake Kilpisjärvi ice in 2013 and 2014. Downwelling scalar PAR irradiance above the ice and beneath the ice (for 2014 also inside ice $24 \mathrm{~cm}$ from ice bottom), and estimated daily attenuation coefficient of ice based on the measurements at solar noon. 
Tab. 3. Daily averages of the surface heat flux terms during the 2013 and 2014 field campaigns at Lake Kilpisjärvi.

\begin{tabular}{|c|c|c|c|c|}
\hline Day May/June 2013 & Solar flux at surface & Net longwave radiation & Latent heat flux & Sensible heat flux \\
\hline 23 & 93 & -24 & -12 & 26 \\
\hline 24 & 96 & -23 & -10 & 22 \\
\hline 25 & 87 & -32 & -18 & 30 \\
\hline 26 & 69 & -6 & -15 & 28 \\
\hline 27 & 94 & 5 & -21 & 45 \\
\hline 28 & 89 & 9 & -14 & 30 \\
\hline 29 & 89 & 3 & -14 & 31 \\
\hline 30 & 95 & 8 & -10 & 23 \\
\hline 31 & 94 & 13 & -14 & 33 \\
\hline 1 & 72 & 24 & -17 & 39 \\
\hline 2 & 41 & 20 & -5 & 18 \\
\hline 3 & 45 & 20 & -16 & 38 \\
\hline Mean & 80 & 1.4 & -13.8 & 30.3 \\
\hline Day May 2014 & Solar flux at surface & Net longwave radiation & Latent heat flux & Sensible heat flux \\
\hline 20 & 52 & -15 & -3 & 6 \\
\hline 21 & 57 & -24 & -6 & 9 \\
\hline 22 & 27 & -13 & -9 & 9 \\
\hline 23 & 39 & -15 & -7 & 9 \\
\hline 24 & 85 & -36 & -13 & 17 \\
\hline 25 & 49 & 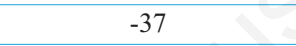 & -11 & 6 \\
\hline 26 & 62 & 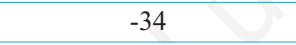 & -7 & -3 \\
\hline 27 & 83 & -62 & -4 & 4 \\
\hline 28 & 78 & -49 & -4 & 7 \\
\hline Mean & 59.1 & -31.7 & -7.1 & 7.1 \\
\hline
\end{tabular}

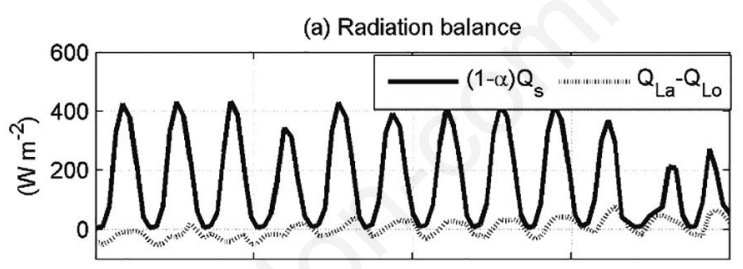

(b) Turbulent heat fluxes

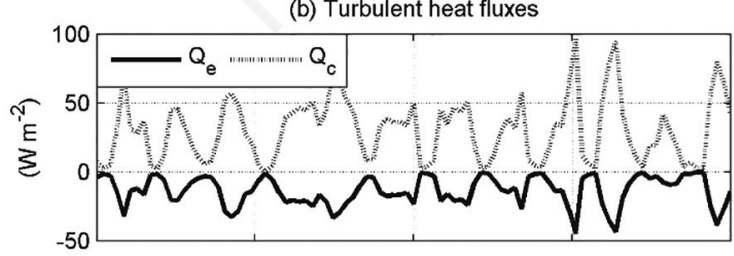

(c) Heat budget of the surface $Q_{n}$

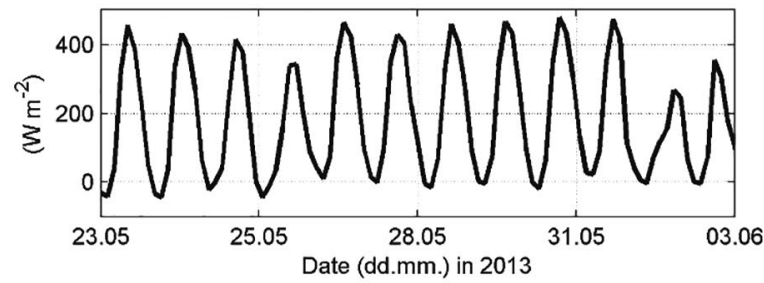

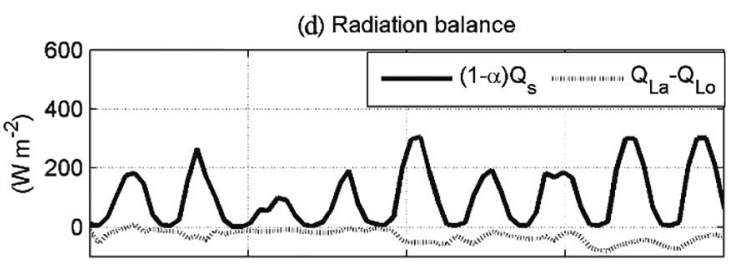

(e) Turbulent heat fluxes

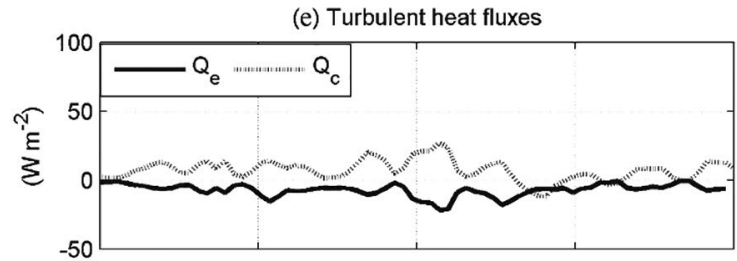

(f) Heat budget of the surface $Q_{n}$

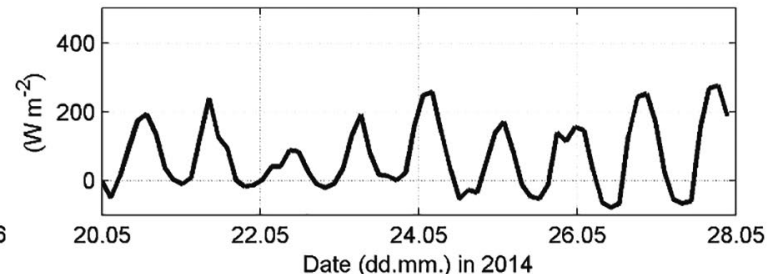

Fig. 6. Surface heat budget in 2013 (a-c) and 2014 (d-f) in Lake Kilpisjärvi. a,d) net solar radiation and net longwave radiation; b,e) turbulent latent and sensible heat fluxes; $c, f)$ total heat budget of the lake ice. 
3). Expectedly, net longwave radiation stayed negative over the whole field campaign, and the daily averages varied between $-13 \mathrm{~W} \mathrm{~m}^{-2}$ and $-62 \mathrm{~W} \mathrm{~m}^{-2}$. The turbulent heat exchange (TF) was rather weak and altogether did not contribute any notable heat flux to the ice (Fig. 6e). Sensible heat flux remained slightly positive the maximum peaking to $50 \mathrm{~W} \mathrm{~m}^{-2}$, except for May 26 turning negative.

The daily averages ranged from $-3 \mathrm{~W} \mathrm{~m}^{-2}$ to $17 \mathrm{~W} \mathrm{~m}^{-2}$ (Tab. 3). Similarly, latent heat flux stayed low, between zero and $-20 \mathrm{~W} \mathrm{~m}^{-2}$, with daily averages from $-3 \mathrm{~W} \mathrm{~m}^{-2}$ to $-13 \mathrm{~W} \mathrm{~m}^{-2}$. The estimated Bowen ratio was -1.1 and the mean turbulent heat flux was zero. The sum of the rather small surface heat balance terms resulted in restrained net amount of heating (Fig. 6f). At night, the ice was cooled down by $-40 \mathrm{~W} \mathrm{~m}^{-2}$, but the daytime positive values peaking to $240 \mathrm{~W} \mathrm{~m}^{-2}$ compensated for the night losses, and on daily average the surface was gaining heat at rates between 7 and $53 \mathrm{~W} \mathrm{~m}^{-2}$.

The heat flux from water to ice bottom is the most uncertain part of the heat budget. For 2014, this flux was estimated from temperature and turbulence measurements in the ice-water boundary layer as $5-10 \mathrm{~W} \mathrm{~m}^{-2}$ (Kirillin et al., 2018). It corresponds to melting of ice by $0.14-0.28$ $\mathrm{cm}$ per day, which was quite small compared to the surface heat balance or the heat used in internal melting. The ratio of the heat flux from water to ice to the solar radiation flux transmitted to the water averaged to about 0.3 based on our data and Kirillin et al. (2018). Thus, most of the sunlight reaching the water was used for water warming. In 2013 no detailed measurements were performed in the ice-water boundary layer. Assuming that the ratio between the heat flux from water to ice and the solar radiation was the same in 2013 and 2014, the heat flux from water to ice in 2013 should reach $15-20 \mathrm{~W} \mathrm{~m}^{-2}$. These relatively large values were apparently caused by the thinner and more clear ice cover. Also, as shown below, both 2013 and 2014 heat flux estimates are consistent with the total heat budget of the ice cover.

\section{Ice melting rates}

The net surface heat fluxes and the redistribution of solar radiation between the surface and interior (see
Section Light transfer through ice above) demonstrate that the ice melting at the surface and inside ice dominated, while the bottom melting was a smaller factor in both cases, 2013 and 2014. The agreement between the heat budget and observed ice melting is quite good: The measured ice thickness change corresponded to the sum of surface melting, bottom melting, and collapse of ice internal layers due to internal deterioration, calculated from the heat fluxes (Tab. 4; Fig. 7). In 2013 internal
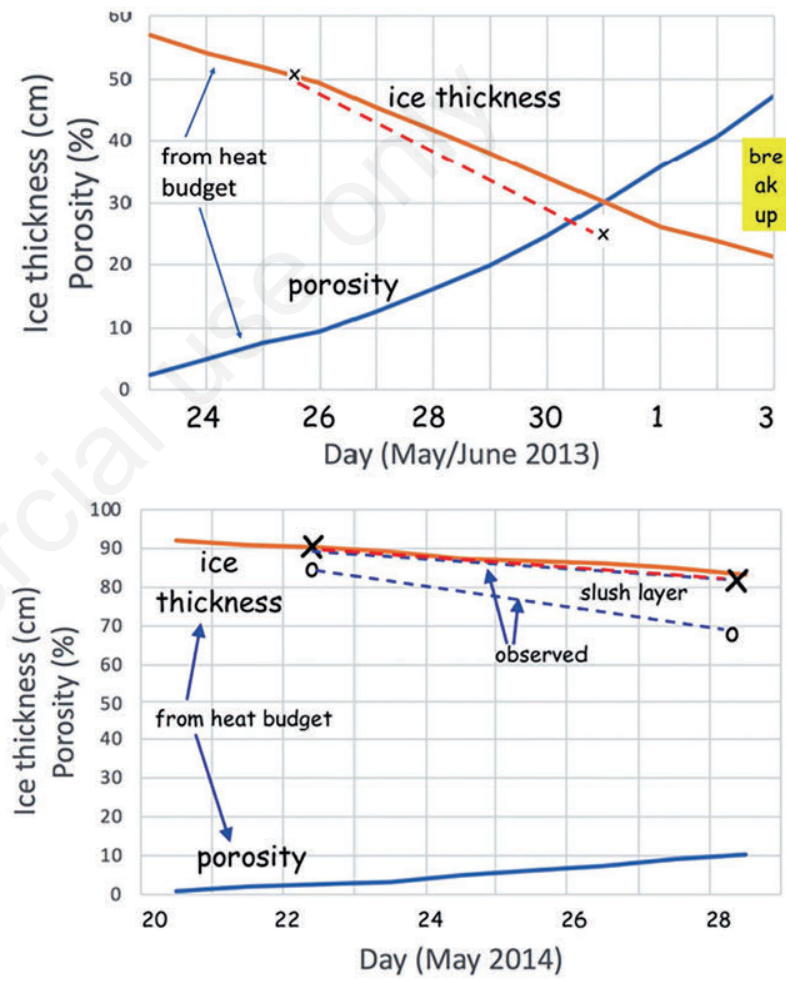

Fig. 7. Evolution of ice thickness and porosity in 2013 and 2014. Ice thickness is shown by the red lines based on surface and bottom heat fluxes and crosses $(\mathrm{x})$ for direct data. Porosity is given by blue lines based on measured absorption of sunlight in the ice. The slush layer based on direct data is shown for 2014 and breakup day by the yellow mark for 2013 .

Tab. 4. Melting of ice during the field campaigns. The numbers present average \pm standard deviation of melt rate in $\mathrm{cm} \mathrm{day}^{-1}$. Year 2013

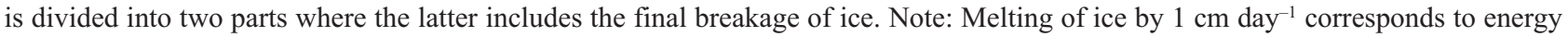
flux of $35 \mathrm{~W} \mathrm{~m}^{-2}$.

\begin{tabular}{lccccc} 
& & \multicolumn{2}{c}{ Estimated from heat budget } & & \multicolumn{2}{c}{$\begin{array}{c}\text { Measured } \\
\text { Period }\end{array}$} & Surface melting & Internal melting & Bottom melting & Total melting & ice thickness change \\
23-31 May 2013 & $2.9 \pm 0.6$ & $1.0 \pm 0.3$ & $0.5 \pm 0.1$ & $4.4 \pm 0.5$ & 5.0 \\
\hline 1-3 June 2013 & $2.7 \pm 0.6$ & $0.3 \pm 0.1$ & $0.4 \pm 0.1$ & $3.3 \pm 0.9$ & 8.3 (ice breakage) \\
\hline 20-28 May 2014 & $0.8 \pm 0.4$ & $1.0 \pm 0.3$ & $0.1 \pm 0.0$ & $1.9 \pm 0.6$ & 1.3
\end{tabular}


melting was slightly higher than surface melting (Fig. 7a) but in 2014 the surface melting was dominant (Fig. 7b). The agreement between the heat budget and observed ice melting is quite good. In 2013, the ice disappeared fast in the beginning of June due to mechanical breakage (Fig. 7a) that produced an apparent rate of thickness decrease by $8.3 \mathrm{~cm}$ per day. Fig. 7a shows how the breakage event was preceded by increase of ice porosity to a critical level.

\section{DISCUSSION}

There has not been much field research on ice melting due to the difficult conditions with unstable, deteriorating ice cover. It is known that ice melts at the upper and lower boundaries and in the interior, but the quantification of their fractions is not available from empirical data (Leppäranta, 2015). Here, we have shown that the fractions depend on the prevailing weather and the structure of ice. The melting at the ice bottom remains the most uncertain component of the heat budget. Its contribution to the ice cover melt may vary in a wide range depending on the stage of the ice melting period, hydrodynamic properties of the under-ice boundary layer, and the amount of heat stored in the water column during winter (Kirillin et al., 2018). These effects require further quantification based on field data.

In the net radiation balance the most uncertain factor is the ice surface albedo. This was not directly measured in this study. Instead, results from earlier field campaign from the same lake were utilized, and controlled with solar radiation measurements in ice and beneath ice. However, the albedo choice was not arbitrary since the radiation transfer measurements provide limiting control for the estimation. Since the surface heat budget agreed quite well with the observed ice melting, the surface neat budget was apparently well represented.

Jakkila et al. (2009) found a strongly falling albedo in the beginning of the melting period and then first increasing and then decreasing in ice transmittance due to internal melting and changes in the amount of gas pockets and water-filled pockets in ice. They had heat flux to the ice bottom estimated as $12 \mathrm{~W} \mathrm{~m}^{-2}$ that was about one-third of the internal melting, but the average surface heat balance was negative. The latitude was $61^{\circ} \mathrm{N}$, much lower than Kilpisjärvi $\left(69^{\circ} \mathrm{N}\right)$. Leppäranta et al. (2010) studied one lake in Russian Karelia in the melting seasons of 2006 and 2007. The transmittance was around 0.2 in 2006 but increased from 0.1 to 0.5 in 2007 , and also here the stable transmittance case was connected with a large fraction of snow-ice.

The stratification over a cold surface of melting ice is stable that suggests a strong damping of the turbulent heat exchange. This suggestion is supported by results from the "normal" case of 2014. However, in the "extremely warm" melting period of 2013 the turbulent fluxes were high concurrently with the exceptionally high air temperatures. Hence, dynamics of the air-ice boundary layer was apparently turbulent. The situation is mirrored at the bottom of the ice cover, where stable stratification is produced by radiative heating of water, while ice-water boundary stays at the melting point. Sources of turbulence in these extremely strong stable conditions require more detailed investigations.

Ice melting is a long process: In Kilpisjärvi, for the nearly $1 \mathrm{~m}$ thick ice cover, ice melting period typically takes one month, preceded by a month of melting of the snow cover. The critical time for melting start is the zero upcrossing of the ice heat budget (Leppäranta et al., 2017), taking place in Kilpisjärvi around mid-April. After melting has started, it is difficult to stop due to a strong positive (albedo) feedback. The present experimental data is from the late melting stage, when ice was melting at both boundaries and in the interior. In 2013 the melting could be monitored at its latest stage down to the ice break.

The present results on the heat budget during the ice melt shed light on the physical mechanisms behind seasonal formation of ice cover in different climatic conditions. Lake Kilpisjärvi ice climatology shows the mean breakup date as June 18, with standard deviation of $8.8 \mathrm{~d}$ (Tab. 1). The corresponding statistics of the freezing date are November 8 and 8.2 d (Leppäranta et al., 2017). In southern Finland, the mean freezing date is four weeks later but the breakup date is seven weeks earlier. The standard deviation of the breakup date is the same in south and north but $50 \%$ more for the freezing date in south. The longer gap in melting than in freeze-up may be attributed to more snow accumulation and more ice thickness in the north. In that sense, southern high-altitude regions, like the Tibetan Plateau lakes may provide a useful case for comparison: There, both freezing and breakup dates correspond to those of southern Finland, while temperature conditions correspond rather to those of arctic tundra climate (Yao et al., 2016), similar to Kilpisjärvi. The high level of solar radiation (combined with very low snowfall and, consequently, high ice transparency) create there a unique relationship between the radiation balance and the turbulent fluxes, similar to the "extreme" conditions of 2013 in Kilpisjärvi, and leading to shortening of ice cover period. The major findings of the present study on the decisive role of the radiation/surface fluxes for the ice cover melt, when further generalized, will provide the necessary quantitative information to estimate the seasonal ice response to climate change in different climatic conditions.

Lake ice models provide the temperature and thickness of ice, advanced models also include sublayers 
of the ice cover. In the melting stage, internal melting results in increasing porosity as shown by the present field data. With known, assumed or modelled optical properties of ice, it is possible to include internal melting and porosity in lake ice models. Then the mechanical breakage of ice can be also included at the time the porosity reaches the critical level. An extension would be to examine the strength of ice as a function of porosity to also model the bearing capacity of the ice as well as ice loads. In freshwater lakes the approach is feasible but in saline lakes brine dynamics rises further complications.

\section{CONCLUSIONS}

Field research was carried through in a medium-size arctic tundra lake, Kilpisjärvi, Finland, in the ice melting periods of 2013 (an extreme warm spring) and 2014 (normal spring). The purpose was to examine the deterioration of the ice cover with its driving forces. The heat budget was dominated by the radiation balance; turbulent heat fluxes were large in 2013 due to warm air advection but small in 2014. In the beginning of the field periods, ice thickness was $60 \mathrm{~cm}$ in 2013 and $90 \mathrm{~cm}$ in 2014, with snow-ice absent in 2013 but accounting for $50 \%$ of the ice cover in 2014 . The mean net solar radiation was $160 \mathrm{~W} \mathrm{~m}^{-2}$ in 2013 and $118 \mathrm{~W} \mathrm{mv}$ in 2014, and the mean net longwave radiation was nearly zero in 2013 but normal $\left(-31 \mathrm{~W} \mathrm{~m}^{-2}\right)$ in 2014. The Bowen ratio was negative, and the average total turbulent flux was $15 \mathrm{~W}$ $\mathrm{m}^{-2}$ in 2013 and zero in the following year.

Transmittance of solar radiation through the ice was 0.25 in 2013 and 0.10 in 2014. The estimated melting rate was $4.4 \mathrm{~cm} \mathrm{~d}^{-1}$ in 2013, $1.9 \mathrm{~cm} \mathrm{~d}^{-1}$ in 2014 , distributed to surface, ice interior, and ice bottom with fractions, respectively, 2.9, 1.0 and $0.5 \mathrm{~cm} \mathrm{~d}^{-1}$ in 2013 and $0.8,1.0$ and $0.1 \mathrm{~cm} \mathrm{~d}^{-1}$ in 2014. Internal deterioration increased the porosity of ice, and in 2013 a rapid ice breakage event completed the ice breakup in short time when ice porosity had reached 40-50\%. In 2014 the field period ended three weeks before ice breakup and the porosity reached only $11 \%$.

Melting of lake ice is an accelerating process due to the positive albedo feedback, as is well seen in the patchiness of the ice surface in the melting period. Ice thickness decreases and ice porosity increases that leads to a catastrophic end when the fragile ice breaks under its own weight. Further observations are needed, in particular to directly measure melting at the surface, interior and bottom, together with the heat fluxes, that would guide to understand the full picture and model parameters. This is demanding task, since melting lake ice is difficult and risky to work with. Mathematical modelling of the physics of the melting process necessitates the use of a two-phase model with thickness and porosity as the modelled variables (see eqs. 3). A largely open question is that at which porosity the ice breaks. After breakage the remaining ice blocks melt rapidly using the heat accumulated into the water body.

\section{ACKNOWLEDGMENTS}

The field campaigns were performed in frames of the EU FP7 Program "International Network for Terrestrial Research and Monitoring in the Arctic (INTERACT)" via transnational access projects "Solar convection and lateral currents under lake ice cover (CONCUR)" and "Lake circulation during polar night in Arctic (LACUNA)". We thank the participants of the Lake Kilpisjärvi field campaigns in 2013 and 2014, and also acknowledge the personnel of the Kilpisjärvi Biological Station who provided us with logistical support.

The research is part of the research project "IceBound" funded by the German Science Foundation (DFG project KI 853/11-1) and Russian Foundation for Basic Research (RFBR Project 15-55-12378 NNIO a). GK was supported by DFG projects KI 853/11-2 and KI 853/13-1. GK and LW were supported by the SinoGerman Center (Research Project GZ1259).

The work is a contribution of the National Natural Science Foundation of China (91637107), the Nordic Centre of Excellence Cryosphere-Atmosphere Interactions in a Changing Arctic Climate (CRAICC), the Opening Research Foundation of Key Laboratory of Land Surface Process and Climate Change in Cold and Arid Regions, Chinese Academy of Sciences (LPCC 201501).

\section{REFERENCES}

Arst H, Erm A, Leppäranta M, Reinart A, 2006. Radiative characteristics of ice-covered fresh- and brackish-water bodies. Proc. Estonian Acad. Sci. Geology 55:3-23.

Ashton G, 1986. River and lake ice engineering. Water Resources Publications, Littleton: 485 pp.

Bengtsson L, 1996. Mixing in ice-covered lakes. Hydrobiologia 322:91-97.

Benson BJ, Magnuson JJ, Jensen OP, Card VM, Hodgkins G, Korhonen J, Livingstone DM, Stewart KM, Weyhenmeyer GA, Granin NG, 2012. Extreme events, trends, and variability in Northern Hemisphere lake-ice phenology (1855-2005). Clim. Change 112: 99-323.

Bernhardt J, Engelhardt C, Kirillin K, Matschullat J, 2012. Lake ice phenology in Berlin-Brandenburg from 1947-2007: observations and model hindcasts. Clim. Change 112:791-817.

Duan A, Xiao Z, 2015. Does the climate warming hiatus exist over the Tibetan Plateau? Sci. Rep. 5:13711, DOI: $10.1038 /$ srep 13711

Guo D, Wang H, 2012. The significant climate warming in the northern Tibetan Plateau and its possible causes. Int. J. Climatol. 32:1775-1781. 
Jakkila J, Leppäranta M, Kawamura T, Shirasawa K, Salonen $\mathrm{K}, 2009$. Radiation transfer and heat budget during the ice season in Lake Pääjärvi, Finland. Aquat. Ecol. 43:681-692.

Karetnikov S, Leppäranta M, Montonen A, 2017. Time series over 100 years of the ice season in Lake Ladoga. J. Great Lakes Res. 43:979-988.

Kelley D, 1997. Convection in ice-covered lakes: effects on algal suspension. J. Plankton Res. 19:1859-1880.

Kirillin G, Leppäranta M, Terzhevik A, Granin N, Bernhardt J, Engelhardt C, Efremova T, Golosov S, Palshin N, Sherstyankin P, Zdorovennova G, Zdorovennov R, 2012. Physics of seasonally ice-covered lakes: a review. Aquat. Sci. 74:659-682

Kirillin G, Forrest AL, Graves K, Fischer A, Engelhardt C, Laval BE, 2015. Axisymmetric circulation driven by marginal heating in ice-covered lakes. Geophys. Res. Lett. 42:28932900

Kirillin G, Aslamov I, Leppäranta M, Lindgren E, 2018. Turbulent mixing and heat fluxes under lake ice: the role of seiche oscillations. Hydrol. Earth Syst. Sci. 22:6493-6504.

Kohout T, Bućko MS, Rasmus K, Leppäranta M, Matero I, 2014. Non-destructive investigation of a palsa using groundpenetrating radar. Permafrost Periglac. 25:45-52.

Korhonen J, 2006. Long-term changes in lake ice cover in Finland. Hydrol. Res. 37: 47-363.

Lei R, Leppäranta M, Erm A, Jaatinen E, Pärn O, 2011. Field investigations of apparent optical properties of ice cover in Finnish and Estonian lakes in winter 2009. Estonian J. Earth Sci. 60:50-64.

Lei R, Leppäranta M, Cheng B, Heil P, Li Z, 2012. Changes in ice-season characteristics of a European Arctic lake from 1964 to 2008. Clim. Change 115:725-739.

Leppäranta M, 2015. Freezing of lakes and the evolution of their ice cover. Springer-Praxis, Heidelberg: 301 pp.

Leppäranta M, Lindgren E, Shirasawa K, 2017. The heat budget of Lake Kilpisjärvi in the Arctic tundra. Hydrol. Res. 48:969-980.

Leppäranta M, Myrberg K, 2009. Physical Oceanography of the Baltic Sea. Praxis Publishing, Chichester: 378 pp.

Leppäranta M, Terzhevik A, Shirasawa K, 2010, Solar radiation and ice melting in Lake Vendyurskoe, Russian Karelia. Hydrol. Res. 41:50-62.

Ma RH, Yang GS, Duan HT, Jiang JH, Wang SM, Feng XZ, Li
AN, Kong FX, Xue B, Wu JL, Li SJ, 2011. China's lakes at present: number, area and spatial distribution. Sci. China Earth Sci. 54:283 -289 .

Magnuson J, Robertson D, Benson B, Wynne R, Livingstone D, Arai T, Assel R, Barry R, Card V, Kuusisto E, Granin N, Prowse T, Stewart K, Vuglinski V, 2000. Historical trends in lake and river ice cover in the Northern Hemisphere. Science 289:1743-1746.

Malm J, Bengtsson L, Terzhevik A, Boyarinov P, Glinsky A, Palshin N, Petrov M, 1998. Temperature and salt content regimes in three shallow ice-covered lakes. Nordic Hydrol. 28:129-152.

Masterson DM, 2009. State of the art of ice bearing capacity and ice construction. Cold Reg. Sci. Technol. 58:99-112.

Mironov D, Terzhevik A, Kirillin G, Jonas T, Malm J, Farmer D, 2002. Radiatively driven convection in ice-covered lakes: observations, scaling, and a mixed layer model. J. Geophys. Res. 107. Doi:10.1029/2001JC000892, 2002.

Reinart A, Arst H, Blanco-Sequeiros A, Herlevi A, 1998. Relation between underwater irradiance and quantum in dependence on water transparency at different depths in the water bodies. J. Geophys. Res. 103:7749-7752.

Salonen K, Leppäranta M, Viljanen M, Gulati R, 2009. Perspectives in winter limnology: closing the annual cycle of freezing lakes. Aquat. Ecol. 43:609-616.

Tranvik L, 2014. Carbon cycling in the Arctic. Science 345:870-870.

Walter KM, Edwards ME, Grosse G, Zimov SA, Chapin FS III, 2007. Thermokarst lakes as a source of atmospheric $\mathrm{CH} 4$ during the last deglaciation. Science 318:633-636.

Wen L, Lyu S, Kirillin G, Li Z, Zhao L, 2016. Air-lake boundary layer and performance of a simple lake parameterization scheme over the Tibetan highlands. Tellus A 68:31091.

Yang Y, Cheng B, Kourzeneva E, Semmler T, Rontu L, Leppäranta M, Shirasawa K, Li Z, 2013. Modelling experiments on air-snow interactions over Kilpisärvi, a lake in northern Finland. Boreal Environ. Res. 18:341-358.

Yao X, Li L, Zhao J, Sun M, Li J, Gong P, An L, 2016. Spatialtemporal variations of lake ice phenology in the Hoh Xil region from 2000 to 2011. J. Geograph. Sci. 26:70-82.

Zimov SA, Schuur EAG, Chapin FS, 2006. Permafrost and the global carbon budget. Science 312:1612-1613. 